\title{
INSTRUÇÕES METODOLÓGICAS ESTATAIS E DIREÇÕES AO PROFESSOR NOS LIVROS DIDÁTICOS VOLTADOS AO ENSINO SECUNDÁRIO (1930-1960)
}

\section{STATE GUIDELINES AND METHODOLOGY INSTRUCTIONS FOR TEACHERS IN SECONDARY EDUCATION TEXTBOOKS (1930-1960)}

\author{
Fábio Ribeiro \\ Professor da Secretaria de Educação do Estado de São Paulo e da Secretaria Municipal de \\ Educação de São Paulo, Brasil \\ Mestre em História Social pela Universidade de São Paulo, Brasil \\ e-mail: fabiohist@hotmail.com
}

DOI:

http://dx.doi.org/10.26512/hh.v5i10.10997

Recebido em 10 de novembro de 2016

Aprovado em 04 de outubro de 2017

\section{RESUMO}

O artigo objetiva analisar a presença de orientações aos professores em livros didáticos direcionados ao ensino secundário, editados no Brasil entre 1930 e 1960. O livro escolar é concebido com vistas ao aluno, porém, sua escolha e uso em sala de aula dependem da ação do professor, que muitas vezes o utiliza no preparo de aulas. A partir da década de 1930, o Estado assume a tarefa de prover o ensino secundário de programas curriculares e de instruções metodológicas voltadas ao docente. Sob a perspectiva da História Cultural, analisa livros de diferentes disciplinas, identificando o conteúdo das instruções, de que maneira dialogam com as direções metodológicas estatais e com o modelo pedagógico em voga. Conclui que os textos direcionados ao professor não são frequentes nos compêndios, têm caráter pouco prescritivo e que as instruções oficiais raramente aparecem nos livros escolares.

Palavras-Chave: livro didático; orientações ao professor; instruções metodológicas.

\begin{abstract}
This article aims to analyze the presence of guidance to teachers in textbooks focused on secondary education edited in Brazil between 1930 and 1960. The textbook is designed for students, however, its choice and use in the classroom depend on the teacher's action, which often uses it in the preparation of lessons. From the 1930's, the State assumes the task of providing the secondary education with curriculum programs and methodological instructions aimed at the teacher. From the perspective of Cultural History, it analyzes books of different subjects, identifying the contents of the instructions, the way they discuss with Government methodological directions and with the current pedagogical model. It concludes that texts aimed at teachers are not common in textbooks, have little prescriptive nature and official instructions rarely appear in school textbooks.
\end{abstract}

Keywords: textbook. guidance to the teacher; methodological instructions. 
O escritor Pedro Nava, ao narrar sua experiência estudantil no Colégio Pedro II no início do século XX, descreve as aulas de História:

Mas o quarto ano nos reservava ainda jóia do mais subido quilate. João Ribeiro. Foi nosso professor de universal em 1919 e de História do Brasil em 1920... Infelizmente o que aprendemos de História foi diretamente nos livros de mestre João Ribeiro porque ele não prelecionava. Marcava lição. Na próxima vez é o capítulo XXIII: Maomé e o Islamismo. A Invasão dos Árabes. E quero tudo na ponta da língua. ${ }^{1}$

A despeito do enfado que a metodologia adotada pelo professor João Ribeiro provocava no autor, pode-se extrair desta passagem um interessante retrato da relação que o docente mantinha com o livro didático em sala de aula. Mesmo tratando-se de um renomado professor - inclusive autor de livros escolares -, lecionando num colégio modelar do período, observa-se o compêndio como importante material de apoio ao trabalho docente.

A proposta deste artigo é investigar a existência de orientações direcionadas ao professor em livros didáticos do nível secundário, publicados entre 1930 e 1960, buscando identificar o teor destas instruções, de que forma dialogam com as instruções metodológicas estatais e com os modelos pedagógicos em voga. O conteúdo aqui apresentado deriva de capítulo da dissertação de mestrado defendida no Departamento de História da FFLCH/USP. ${ }^{2}$

A análise se inicia em 1930. A chegada de Getúlio Vargas ao poder assinalou um ciclo caracterizado pelo fortalecimento do poder central também no campo educacional. A realização de duas Reformas Educacionais, a criação da Comissão Nacional do Livro Didático (CNLD), em 1938 - órgão responsável pela primeira estrutura estatal em nível nacional de avaliação e controle dos livros escolares -, e o caráter acentuadamente prescritivo da legislação relativa à educação refletem este controle do Estado. A partir de meados dos anos 1920, um novo modelo pedagógico se estabeleceu, ganhando força a partir da década de 1930. Centrado no ideário da chamada pedagogia da Escola Nova, pretendia subsidiar a

\footnotetext{
${ }^{1}$ NAVA, Pedro. Chão de Ferro - memórias/3. Rio de Janeiro: José Olympio, 1976, p. 240-241.

${ }^{2}$ RIBEIRO, Fábio. Título. 2015. 183f. Dissertação (Mestrado) - Departamento de História da Faculdade de Filosofia, Letras e Ciências Humanas, Universidade de São Paulo, São Paulo, 2015. Disponível em http://www.teses.usp.br/teses/disponiveis/8/8138/tde-26052015-110034/pt-br.php. Nesta pesquisa procurei investigar a presença de orientações aos docentes em livros escolares direcionados ao nível primário e secundário, editados no Brasil em três períodos (1880 a 1930, 1930 a 1960 e 1966 a 1985).
} 
prática do professorado com um conjunto de saberes autorizados e via na publicação de Bibliotecas Pedagógicas o espaço para a divulgação de métodos de ensino. O modelo implementado a partir de 1930 pautou a educação nacional durante mais de três décadas. ${ }^{3}$ Assim, o marco final em 1960 representou o momento final deste ciclo.

A fonte precípua a ser interrogada neste trabalho é o livro didático. Obviamente, o volume de obras editadas no período esquadrinhado é imenso. Considerando que a presença de instruções era exceção, não regra, estabelecer muitos parâmetros para a escolha dos livros - tais como disciplina, autor e editora - poderia conduzir à exclusão de informações relevantes. Assim, dentro da baliza temporal estabelecida, foram buscados no Banco de Dados de Livros Escolares Brasileiros - LIVRES -, da Biblioteca do Livro Didático da Faculdade de Educação da USP ${ }^{4}$, e na página do Laboratório de Ensino e Material Didático (LEMAD) do Departamento de História da FFLCH/USP ${ }^{5}$ referências a livros didáticos voltados ao ensino secundário que trouxessem algum tipo de diálogo com o docente.

É importante destacar que, apesar de ter investigado livros didáticos de diferentes disciplinas, foram priorizados exemplos do campo do ensino de História. A análise do conteúdo das Instruções Metodológicas estatais publicadas em 1931, 1942 e 1951, por exemplo, foi centrada nas informações referentes à área de História ${ }^{6}$.

Se o trabalho de identificação e diferenciação de um livro didático em relação aos demais livros não parece ser tarefa árdua, devido às características bastante particulares que apresenta quanto a mercado, consumo, tiragens, preço, elaboração e comercialização, o mesmo não se pode dizer do ato de defini-lo. É o livro didático um objeto multifacetado. $\mathrm{Na}$ sua dimensão material pode ser pensado como uma mercadoria vinculada à lógica da indústria cultural e do capitalismo editorial. Ao mesmo tempo, é um suporte de conhecimentos escolares que são propostos pelos currículos educacionais - nesse aspecto o Estado surge como um agente vinculado à produção didática, pois é dele a prerrogativa de elaboração dos currículos nos

\footnotetext{
${ }^{3}$ SOUZA, Rosa Fátima de. História da organização do trabalho escolar e do currículo no século XX: (ensino primário e secundário no Brasil). São Paulo: Cortez, 2008, p. 80.

${ }^{4}$ A consulta ao sistema LIVRES, da Biblioteca do Livro Didático da Faculdade de Educação da USP, está disponível em http://www2.fe.usp.br:8080/livres/\# (acesso em 03/09/2016).

5 A página do Laboratório de Ensino e Material Didático (LEMAD) do Departamento de História da FFLCH/USP permite a consulta ao acervo da biblioteca do Laboratório. Disponível em http://lemad.fflch.usp.br/acervo022013 (acesso em 03/09/2016).

${ }^{6}$ A preferência por exemplos do campo de História deve-se ao fato de ser esta a área de concentração da pesquisa, além de se configurar impraticável para os limites deste trabalho abordar todas as matérias de ensino.
} 
quais os materiais didáticos se baseiam, bem como é ele que avalia e aprova tais materiais. Mas o livro didático é também suporte de métodos pedagógicos, quando sugere formas de trabalho e estratégias para o professor, instrumentos de avaliação do conteúdo, etc. Por fim, é veículo de um sistema de valores, ideologias e da cultura de uma época. ${ }^{7}$

Allain Chopin, importante estudioso do livro didático, elenca quatro funções essenciais que tal obra exerce: referencial, instrumental, ideológica e cultural/documental. Ao detalhar a função instrumental, afirma:

o livro didático põe em prática métodos de aprendizagem, propõe exercícios ou atividades que, segundo o contexto, visam a facilitar a memorização dos conhecimentos, favorecer a aquisição de competências disciplinares ou transversais, a apropriação de habilidades, de métodos de análise ou de resolução de problemas, etc. ${ }^{8}$

As múltiplas facetas/funções assumidas pelo livro escolar, em geral, o vinculam ao processo de formação do aluno. Mas ele cumpre um importante papel em relação ao professor.

Antonia Terra de Calazans Fernandes, em investigação sobre a memória de usuários de livros didáticos, apresenta a lembrança de uma professora acerca do uso deste material em sua prática cotidiana:

Eu sempre tive dificuldade de usar um só, usar um só. Mas eu sempre achei muito importante recorrer a livro didático. Geralmente utilizava pra uma coisa, introduzia outras. No primário, por exemplo, minha experiência foi mais de pegar o que o MEC mandava pra escola, porque as crianças não podiam comprar. E de lá eu selecionava, o que eu queria usar de um, do outro, e completava com coisas que eu pegava de outros livros e reproduzia... ${ }^{9}$

Neste estudo, o livro didático é considerado como elemento relevante no processo de construção do conhecimento empreendido pelo professor. Além da função de orientar a prática em sala de aula - por meio da organização do conteúdo, da proposição de exercícios,

\footnotetext{
7 Estas diversas dimensões do livro didático são apresentadas em: BITTENCOURT, Circe Maria Fernandes. Ensino de História: fundamentos e métodos. São Paulo: Cortez, 2004, p. 301-302.

${ }^{8}$ CHOPPIN, Alain. História dos livros e das edições didáticas: sobre o estado da arte. Educação e Pesquisa, São Paulo, v. 30, n. 3, p. 553, set./dez. 2004.

9 FERNANDES, Antonia Terra de Calazans. Livro didático em dimensões materiais e simbólicas. Educação e Pesquisa, São Paulo, v. 30, n. 3, p. 544, set./dez. 2004.
} 
de textos para leitura dos alunos - ele, muitas vezes, é utilizado no preparo de aulas e na elaboração de atividades. ${ }^{10}$

Conceber o livro sob este prisma pressupõe uma reflexão sobre o processo de formação docente. Maurice Tardif, propõe que se pense o professor como sujeito de seu próprio conhecimento e não como mero aplicador de saberes produzidos externamente. " $\mathrm{O}$ trabalho dos professores de profissão deve ser considerado como um espaço prático específico de produção, de transformação e de mobilização de saberes e, portanto, de teorias, de conhecimentos e de saber-fazer específicos ao ofício de professor. "11

Tomando o docente como centro dinâmico de seu próprio ofício, a construção de seus saberes se dá na confluência de três vivências: as experiências pessoais, a formação acadêmica e o cotidiano escolar. Neste último, dentre os diversos componentes que interagem - o contato com outros mestres, a experiência direta com o aluno em sala de aula, as reuniões pedagógicas, o acesso à documentação escolar oficial -, um deles merece destaque: o livro didático.

A base teórica que norteia a análise dos livros escolares fundamenta-se no referencial da História Cultural. Os estudos sobre a História do Livro e da Leitura padecem de um dilema quase edênico: levar em conta o poder condicionante do texto sobre o leitor ou considerar como precípua a liberdade do leitor, que acaba por elaborar sentidos inéditos e não esperados àquilo que foi escrito.

A fim de lidar com esta tensão fundamental, Roger Chartier aconselha o intérprete: “Abordar a leitura é, portanto, considerar, conjuntamente, a irredutível liberdade dos leitores e os condicionamentos que pretendem refreá-la". ${ }^{12}$ As orientações ao docente presentes nos livros didáticos podem ser pensadas como estratégias de que se valem autores e editores a fim de impor uma leitura compulsória ao texto.

\section{As Reformas Francisco Campos (1931) e Gustavo Capanema (1942) e a Portaria Ministerial $n^{\circ} 1.045$ (1951): determinando como ensinar}

\footnotetext{
${ }^{10}$ Já no final do século XIX e início do XX os livros escolares eram uma importante fonte utilizada pelo docente no preparo de suas aulas, bem como instrumento privilegiado do controle estatal sobre o ensino e a aprendizagem. BITTENCOURT, Circe Maria Fernandes. Livro Didático e Saber Escolar 1810-1910. Belo Horizonte: Autêntica, 2008, p. 26; 180.

${ }^{11}$ TARDIF, Maurice. Saberes docentes e formação profissional. 10 ed. Petrópolis: Vozes, 2010, p. 234.

${ }^{12}$ CHARTIER, Roger. A História cultural: entre práticas e representações. Lisboa: Difel, 1990, p. 123.
} 
Desde o início do Governo Provisório, em 1930, a administração de Getúlio Vargas se caracterizou pelo fortalecimento do poder central em detrimento do poder político e econômico dos estados. Este aspecto centralizador também se fez ver no campo educacional. Se nos anos 1920 as iniciativas reformistas partiam dos governos estaduais, com Vargas elas passaram a ter como motor o nível federal.

Marco inicial desse projeto foi a criação, em 1930, do Ministério da Educação e Saúde Pública - promessa da plataforma de governo da Aliança Liberal. Locus privilegiado para a implantação do novo modelo organizacional do sistema escolar, teve como primeiro ocupante Francisco Campos. Durante sua administração, Campos procedeu uma profunda reestruturação da ação estatal no campo da educação secundária e superior.

Por meio do decreto 19.890, de 18/04/1931, o governo federal reorganizou o ensino secundário no país. A duração do curso seria de 7 anos, dividido em dois ciclos - o fundamental, de 5 anos, e o complementar, de 2 anos. A legislação procurou conciliar dois aspectos aparentemente antagônicos deste nível de ensino: o formativo e o propedêutico. O plano de estudos perdeu o caráter humanista que o caracterizou até então, apresentando grande ênfase nas Ciências Físicas e Biológicas.

Segundo Rosa Fátima de Souza, a maior inovação da Reforma Francisco Campos, no que tange à seleção cultural do currículo no secundário, "foi a distribuição mais equilibrada entre estudos literários e científicos no curso fundamental e a revitalização do cientificismo". ${ }^{13}$

A padronização e regulamentação impostos pelo poder Federal estabeleceram maior organicidade ao ensino secundário no Brasil. A exigência de estudos regulares, seriação, frequência obrigatória, aprovação em todas as disciplinas da série para promoção para a série seguinte e habilitação nos dois ciclos para ingresso no ensino superior objetivavam eliminar os cursos preparatórios que atendiam boa parte do alunado do ensino médio.

Apesar das mudanças implementadas pela Reforma criarem condições para que o ramo secundário pudesse atender parte de uma demanda crescente da sociedade brasileira, elas não romperam com o caráter seletivo e estratificado deste nível de ensino. O acesso ao

${ }^{13}$ SOUZA, Rosa Fátima de. História da organização do trabalho escolar e do currículo no século XX: (ensino primário e secundário no Brasil). São Paulo: Cortez, 2008, p. 153. 
primeiro ano ginasial continuava a exigir a aprovação no exame de admissão, uma peneira de trama muito fina por onde poucos passavam. Sobre a função desta prova, Rosa Souza afirma que "O minucioso sistema de avaliação estabelecido pela reforma visava a uma dupla finalidade: moralizar o ensino e legitimar a seletividade do sistema educacional". ${ }^{14}$

Como constatam Marcos Cézar de Freitas e Maurilane Biccas, a dualidade do sistema educacional brasileiro se manteve bem clara no período:

\begin{abstract}
Na chamada "Era Vargas" também circulou com intensidade o discurso que considerava ser "natural" pensar os ensinos secundário e superior para as "mentes aptas a dirigir" e os outros graus e modalidades de ensino destinadas, sem meias palavras, aos pobres, como será o caso explícito do ensino profissionalizante. ${ }^{15}$
\end{abstract}

A criação, por meio do Estatuto das Universidades Brasileiras, de 1931, das Faculdades de Filosofia (ou Educação), Ciências e Letras (FFCL) significou a possibilidade de formação específica ao magistério secundário. A instituição do Registro de Professores junto ao Departamento Nacional de Ensino representou importante passo na regulamentação do trabalho docente, exigindo que candidatos ao exercício do magistério secundário em estabelecimentos públicos e privados se inscrevessem para poder lecionar.

Os programas de ensino das disciplinas do secundário passaram a ser elaborados pelo Ministério da Educação e Saúde Pública, sem que se soubesse quem eram os seus autores, rompendo-se assim uma longínqua tradição que conferia à Congregação do Colégio Pedro II a confecção dos programas.

Guy de Hollanda publicou em 1957 um balanço dos programas e livros didáticos de História elaborados no Brasil entre 1931 e 1956. Ao tratar da reformulação dos programas ocorrida em 1931, afirma:

O propósito que determinou, em 1931, a expedição dos programas de ensino secundário pelo Ministério da Educação e Saúde Pública, parece ter se inspirado num sincero desejo de promover uma radical renovação dos métodos didáticos. ${ }^{16}$

${ }^{14}$ SOUZA, 2008, p. 151.

15 FREITAS, Marcos Cezar de; BICCAS, Maurilane de Souza. História social da educação no Brasil (1926-1996). São Paulo: Cortez, 2009, p. 112.

16 HOLLANDA, Guy. Um quarto de século de programas e compêndios de História para o ensino secundário brasileiro (1931-1956). Rio de Janeiro: Inep/MEC, 1957, p. 14-15. 
Segundo Hollanda, a grande novidade da reforma foi a introdução das "Instruções Metodológicas", precedendo os programas de ensino. "Profundamente inovadoras, com maior ou menor acerto, essas instruções, antes inexistentes ou sumaríssimas, constituíam o aspecto mais positivo da Reforma Francisco Campos". ${ }^{17}$ Contudo, avaliando suas consequências um quarto de século depois, este autor chega a conclusão desanimadora: "Por falta de discussão pública e conveniente divulgação, parecem ter surtido pouco efeito entre o corpo docente". ${ }^{18}$

As instruções para a disciplina de História mostravam-se articuladas à moderna pedagogia da época, propondo ao professor que estimulasse o dom de observação e o poder crítico dos alunos. Sobre as exposições orais - preleções, na terminologia do período, que se tornaram o símbolo do ensino verbalista e livresco da História - as orientações eram taxativas:

O uso das preleções deverá restringir-se ao mínimo possível, ficando principalmente reservado aos casos em que se tiver de fazer a exposição de acontecimentos complexos, da vista de conjunto de uma época ou a caracterização precisa de grandes personalidades. ${ }^{19}$

A ênfase deveria ser no trabalho autônomo dos alunos, principalmente por meio de pesquisas propostas pelos professores. Atividades extraclasse, como visitas a museus, exposições, monumentos, etc., também eram incentivadas. Enfatizava-se o uso de recursos visuais como projeções e mapas. Cabia ao professor orientar e complementar todas estas atividades. A preocupação com o ajustamento entre os exercícios propostos em aula e a idade mental do educando revelam a influência dos estudos de Psicologia aplicados à criança. ${ }^{20}$

Desse modo, a partir da década de 1930, o controle estatal sobre a educação intensificou, abarcando todos os níveis de ensino e os diversos aspectos da vida escolar. Os programas de estudo passaram a trazer anexas instruções metodológicas que retratavam os fundamentos teóricos norteadores das reformas. Os mecanismos de formação do professorado primário e secundário também sofreram modificações. Contudo, até meados

\footnotetext{
${ }^{17}$ HOLLANDA, 1957, p. 16.

${ }^{18}$ HOLLANDA, 1957, p. 16.

${ }^{19}$ BRASIL. Diário Oficial [da] República Federativa do Brasil, Poder Executivo, Rio de Janeiro, 31 jul. 1931, p.12408.

${ }^{20}$ BRASIL. Diário Oficial [da] República Federativa do Brasil, Poder Executivo, Rio de Janeiro, 31 jul. 1931, p.12408.
} 
da década de 1950, outras intervenções estatais no campo educacional foram vistas, em 1942 e 1951.

Dentro da política centralizadora e prescritiva que caracterizou a Era Vargas, em 9 de abril de 1942, o Decreto-lei 4244 estabelecia a Lei Orgânica do Ensino Secundário, conhecida como Reforma Gustavo Capanema - ministro da educação à época. Concebendo o secundário como educação de elites e enfatizando um currículo com formação humanista, a Lei Orgânica retoma tradições que haviam sido alteradas pela Reforma Francisco Campos.

As palavras do próprio ministro Gustavo Capanema retratam com clareza sua concepção sobre as finalidades deste nível de ensino:

É que o ensino secundário se destina à preparação das individualidades condutoras, isto é, homens que deverão assumir as responsabilidades maiores dentro da sociedade e da nação, os homens portadores das concepções e atitudes espirituais que é preciso infundir nas massas, que é preciso tornar habituais entre o povo. Ele deve ser, por isto, um ensino patriótico por excelência, e patriótico no sentido mais alto da palavra, isto é, um ensino capaz de dar aos adolescentes a compreensão da continuidade histórica da pátria. ${ }^{21}$

A Reforma Capanema dividiu o nível secundário em dois ciclos: o ginasial - com duração de 4 anos, voltado a uma formação geral do aluno - e o colegial - que se estendia por 3 anos e bifurcava-se em científico e clássico.

A reorganização curricular estabeleceu 13 disciplinas para o ginásio e 16 para o colegial. O Ministério da Educação e Saúde Pública designaria comissão para elaborar os programas de cada matéria. Tais programas seriam compostos de um sumário da disciplina e da indicação de suas finalidades educativas. A comissão também anexaria as respectivas instruções metodológicas, contendo métodos e processos pedagógicos que os professores deveriam empregar. Tais instruções, contudo, não foram publicadas imediatamente após a entrada em vigor da Lei Orgânica. As do ciclo colegial foram concluídas em 1946 e as do ginasial, apenas no início da década de 1950.

Através da Portaria n 598, de 6 de dezembro de 1945, o Ministério da Educação e Saúde divulgava os Programas e as Orientações Metodológicas para a área de História que

\footnotetext{
${ }^{21}$ BRASIL. Ministério da Educação e Saúde. Ensino secundário no Brasil (organização, legislação vigente, programas). Rio de Janeiro: INEP, 1952 apud SOUZA, 2008, p. 172.
} 
acompanharam a Reforma Capanema, voltadas ao segundo ciclo do curso secundário. A legislação destacava o objetivo do novo programa:

Em resumo, procuram os presentes programas atender a êstes três pontos: "formação de sentido histórico", "compreensão do mundo atual", e "colaboração nos mais altos objetivos culturais da nação", considerados como propósitos fundamentais do ensino histórico neste nível de estudos. 22

Há destaque também para as "técnicas de ensino". O docente deveria

a) Limitar o estudo de datas e nomes próprios aos fatos característicos, ou seja, àqueles que emprestem à evolução histórica o caráter distintivo de cada época, ou de seu episódio central.

[...]

c) Encaminhar o estudo para o terreno das ideias, pela exposição objetiva das teorias e sistemas que presidiram aos grandes movimentos. ${ }^{23}$

Além disso, sugeria um conjunto de estratégias bastante diversificadas para o desenvolvimento da aula: exposição objetiva, proposição de problemas, leitura comentada de grandes textos históricos, ensaios, composições, leituras complementares e método biográfico. ${ }^{24} \mathrm{~A}$ ideia de direcionar a prática docente chegava a tal ponto de detalhamento que até mesmo a duração de cada conteúdo era prescrita:

$\mathrm{Na}$ segunda série, cada uma das duas primeiras unidades pode ser desenvolvida em três semanas; a III e IV, em quatro semanas, cada uma; a V e VI, em duas semanas, cada uma; à unidade VIII, porém, convirá reservar cinco semanas. ${ }^{25}$

O fim do Estado Novo, a promulgação de uma nova Carta constitucional e o envio para o Congresso Nacional de um projeto de Lei de Diretrizes e Bases da Educação colocaram novamente em destaque as demandas educacionais. Em meio a debates acerca da descentralização do ensino, da articulação dos diferentes níveis de ensino, da ampliação do

\footnotetext{
${ }^{22}$ BRASIL. Portaria n ${ }^{\circ}$ 598, de 6 de dezembro de 1945. Diário Oficial [da] República Federativa do Brasil, Poder Executivo, Rio de Janeiro, 15 dez. 1945, Seção I, p. 18758.

${ }^{23}$ BRASIL. Portaria n ${ }^{\circ}$ 598, de 6 de dezembro de 1945. Diário Oficial [da] República Federativa do Brasil, Poder Executivo, Rio de Janeiro, 15 dez. 1945, Seção I, p. 18759.

${ }^{24}$ BRASIL. Portaria n ${ }^{\circ}$ 598, de 6 de dezembro de 1945. Diário Oficial [da] República Federativa do Brasil, Poder Executivo, Rio de Janeiro, 15 dez. 1945, Seção I, p. 18759.

${ }^{25}$ BRASIL. Portaria n ${ }^{\circ}$ 598, de 6 de dezembro de 1945. Diário Oficial [da] República Federativa do Brasil, Poder Executivo, Rio de Janeiro, 15 dez. 1945, Seção I, p. 18759.
} 
acesso ao secundário e da flexibilização curricular, o tema da formação e qualificação docente sobressai. Nesse contexto, o governo federal efetuou uma nova revisão de programas, currículos e instruções metodológicas para o ensino secundário.

Por meio da Portaria Ministerial n 1.045, de 14 de dezembro de 1951, foram divulgadas pelo Ministério da Educação e Saúde os Planos anexos de Desenvolvimento dos Programas Mínimos e as respectivas Instruções Metodológicas para as disciplinas do curso secundário. Se na Reforma de 1942 as orientações aos professores foram divulgadas lentamente ao longo da década de 1940 - e em alguns casos sequer foram publicadas, como as de História para o ginasial - em 1951 a situação foi diferente. Uma única portaria contemplou programas e instruções voltadas aos cursos ginasial e colegial das disciplinas de Português, Francês, Inglês, Espanhol, Latim, Grego, Geografia Geral e do Brasil, Matemática, Desenho, Física, Química, Filosofia, História Geral e do Brasil. Após 20 anos de programas elaborados pelo Ministério da Educação, a congregação do Colégio Pedro II voltava a ter a prerrogativa de confeccionar tais documentos.

Já nas Considerações Preliminares da referida portaria a equipe que elaborou as orientações aos docentes ressalta que "não pretende sugerir inovações em matéria didática, nem ensinar regras de metodologia aos docentes" e que tais instruções objetivam exclusivamente "proporcionar um roteiro, um subsídio, um repositório de esclarecimentos para elucidação de possíveis dúvidas que venham a surgir na execução dos novos programas". Por fim, enfatiza a importância do trabalho do professor: "o que a Congregação deseja acentuar é que o bom êxito na aplicação destes, como de quaisquer programas, depende do zêlo, da boa vontade, do patriotismo dos dignos docentes que os devem pôr em prática na regência de suas turmas. "26

As Instruções Metodológicas voltadas ao ensino de História nos dois ciclos do curso secundário sugeriam o uso dos métodos ativos da pedagogia moderna a fim de ganhar o interesse do aluno através de uma maior vinculação entre o passado e o presente. Propunham que a exposição oral fosse "simples e sucinta", pois o mais recomendável seria privilegiar o trabalho próprio do aluno, que teria "como ponto de partida a utilização pessoal do livro de

\footnotetext{
${ }^{26}$ BRASIL. Portaria n ${ }^{\circ}$ 1.045, de 14 de dezembro de 1951. Diário Oficial [da] República Federativa do Brasil, Poder Executivo, Rio de Janeiro, 22 fev. 1952, Seção I, Suplemento, p. 1.
} 
texto, ameno auxiliar instrumental de trabalho, facilitador da aquisição de conhecimentos, sua fixação e revisão. "27

Portanto, entre 1930 e o início dos anos 1950, o Estado assume a tarefa de prover o ensino secundário não só de programas curriculares, mas também de instruções metodológicas voltadas ao docente. A implantação dos primeiros cursos universitários de licenciaturas no país fez com que, lentamente, começassem a atuar nas escolas secundárias brasileiras profissionais graduados em suas respectivas áreas de ensino. Contudo, a preocupação estatal com as práticas docentes em sala de aula ficava clara através das sucessivas iniciativas de apresentar ao mestre direções não apenas sobre o que ensinar, mas como ensinar.

\section{Orientações aos docentes em livros didáticos voltados ao ensino secundário}

As sugestões metodológicas apresentadas pelo poder público ao longo das décadas de 1930, 1940 e 1950 concordavam em aconselhar o docente no uso de novas estratégias em sala de aula. De maneira geral, propunham o respeito aos interesses, necessidades e experiências do aluno em lugar da centralidade atribuída ao professor e à aquisição do conhecimento.

O livro didático permanecia como material central para o docente. Juliana Filgueiras afirma que os manuais "tornavam-se divulgadores das novas propostas pedagógicas e das novas metodologias de ensino, para os professores que estavam em sala de aula". ${ }^{28}$ Rosa Souza corrobora a opinião: "Os livros didáticos desempenharam um papel importante na disseminação das diretrizes curriculares, traduzindo os princípios doutrinários da Escola Nova em atividades e práticas de ensino". 29

Pensando nessa função do livro escolar como importante veículo de difusão de formas de se ensinar, surgem os questionamentos: de que maneira os compêndios retrataram as novas orientações? Traduziam-nas em prefácios ou notas? Reproduziam-nas conforme

${ }^{27}$ BRASIL. Portaria n ${ }^{\circ}$ 1.045, de 14 de dezembro de 1951. Diário Oficial [da] República Federativa do Brasil, Poder Executivo, Rio de Janeiro, 22 fev. 1952, Seção I, Suplemento, p. 18.

${ }^{28}$ FILGUEIRAS, Juliana Miranda. Os processos de avaliação de livros didáticos no Brasil (1938 - 1984). Tese (Doutorado em Educação) - Pontifícia Universidade Católica, São Paulo, 2011, p. 36.

${ }^{29}$ SOUZA, 2008, p. 85. 
foram publicadas no Diário Oficial? A fim de respondê-los foram investigados 18 livros didáticos voltados ao nível secundário que continham algum tipo de interlocução com o docente $^{30}$, publicados por seis editoras, elaborados por dez autores, referentes às disciplinas de Língua Portuguesa, Canto Orfeônico, História Natural, História, Geografia, Ciências Físicas e Naturais, editados entre 1930 e 1960.

A breve amostra de livros didáticos perscrutada permite observar que era prática comum publicar nos compêndios os programas oficiais, ou afirmar a correspondência entre estes e o índice da obra. Todas as 18 obras investigadas trazem estas informações. E a maior parte se limita a isto (Quadro 1).

Muitos livros estampavam os programas oficiais. Este artifício foi percebido em História Geral para a segunda série ginasial, de João Pereira Vitória ${ }^{31}$, História do Brasil para a terceira e quarta séries ginasiais, de Tito Lívio Ferreira ${ }^{32}$, História Geral para a primeira série ginasial $^{33}$ e História Geral para a quarta série ginasial ${ }^{34}$, ambos de Alcindo Muniz de Souza, História Natural para a quinta série, de Luiz Menezes ${ }^{35}$.

Em algumas obras foi possível observar, além da referência ao currículo estatal, a presença de prefácios e apresentações direcionadas ao docente. É o caso de Geografia, voltado à quinta série secundária, de autoria de Aroldo de Azevedo. Editado em 1937 pela Companhia Editora Nacional como parte da coleção "Biblioteca Pedagógica Brasileira", traz na capa a indicação "de acordo com o programa oficial". $\mathrm{Na}$ "Explicação" que

Quadro 1) Características das orientações ao professor nos livros didáticos voltados ao ensino secundário - 1930-1960. *

\footnotetext{
${ }^{30}$ No catálogo digital do Banco de Dados de Livros Escolares Brasileiros - LIVRES -, da Biblioteca do Livro Didático da Faculdade de Educação da USP, a pesquisa foi feita em intervalos de dez anos entre 1930 e 1960, preenchendo os filtros "Notas" e "Gênero" com os termos "prefácio", "notas", "programa", "instruções metodológicas" "guia" e "manual".

${ }^{31}$ VITÓRIA, João Pereira. História Geral: para a segunda série ginasial. Rio de Janeiro: Francisco Alves, 1947?. (Coleção de Livros Didáticos FTD).

${ }^{32}$ FERREIRA, Tito Lívio. História do Brasil: para a terceira e quarta séries ginasiais. 4 ed. São Paulo: Companhia Editora Nacional, 1947.

${ }^{33}$ SOUZA, Alcindo Muniz de. História Geral: para a primeira série ginasial. São Paulo: Editora Anchieta, 1945.

${ }^{34}$ SOUZA, Alcindo Muniz de. História Geral: para a quarta série ginasial. 4 ed. São Paulo: Companhia Editora Nacional, 1955.

${ }^{35}$ MENEZES, Luiz. História Natural: 5a série. 1 ed. São Paulo: Saraiva, 1935.
} 


\begin{tabular}{|c|c|c|c|c|c|c|c|}
\hline OBRA & AUTOR & 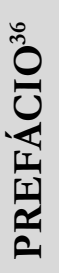 & 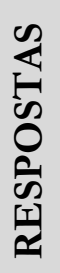 & 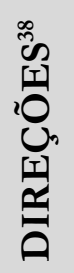 & 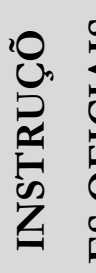 & 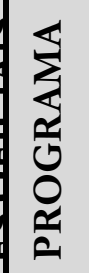 & 颈 \\
\hline $\begin{array}{l}\text { História Geral para a } \\
\text { primeira série ginasial }\end{array}$ & $\begin{array}{c}\text { Alcindo Muniz de } \\
\text { Souza }\end{array}$ & & & & & $X$ & K \\
\hline $\begin{array}{l}\text { História Geral para a } \\
\text { quarta série ginasial }\end{array}$ & $\begin{array}{c}\text { Alcindo Muniz de } \\
\text { Souza }\end{array}$ & & & & & $\mathrm{X}$ & $x$ \\
\hline $\begin{array}{c}\text { Geografia para a quinta } \\
\text { série secundária }\end{array}$ & $\begin{array}{l}\text { Aroldo de } \\
\text { Azevedo }\end{array}$ & $\mathrm{X}$ & & & & $\mathrm{X}$ & K \\
\hline $\begin{array}{l}\text { Geografia Geral para a } \\
\text { segunda série ginasial }\end{array}$ & $\begin{array}{l}\text { Aroldo de } \\
\text { Azevedo }\end{array}$ & $\mathrm{X}$ & & & & $\mathrm{X}$ & K \\
\hline Solfejos $-2^{\circ}$ volume & $\begin{array}{l}\text { Heitor Villa- } \\
\text { Lobos }\end{array}$ & $\mathrm{X}$ & & & $\mathrm{X}$ & $\mathrm{X}$ & K \\
\hline $\begin{array}{l}\text { História Geral para a } \\
\text { segunda série ginasial }\end{array}$ & $\begin{array}{c}\text { João Pereira } \\
\text { Vitória }\end{array}$ & & & & & $\mathrm{X}$ & x \\
\hline \multicolumn{8}{|l|}{ Continuação do Quadro 1} \\
\hline OBRA & AUTOR & 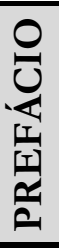 & 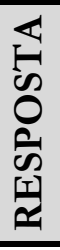 & 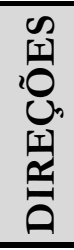 & 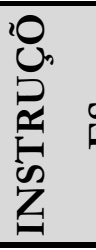 & 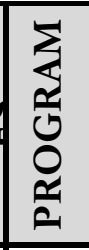 & 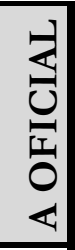 \\
\hline $\begin{array}{c}\text { História da Civilização } \\
\text { para o primeiro ano } \\
\text { ginasial }\end{array}$ & Joaquim Silva & & & & & $\mathrm{X}$ & X \\
\hline
\end{tabular}

${ }^{36}$ Prefácio seria um texto introdutório ou de apresentação elaborado pelo autor do livro didático.

${ }^{37}$ Respostas seriam a apresentação das resoluções ou das respostas dos exercícios propostos ao longo do livro.

${ }^{38}$ Direções seriam orientações - distribuídas no decorrer do compêndio -, direcionadas ao professor, sobre como desenvolver determinado conteúdo ou atividade proposta no livro. 


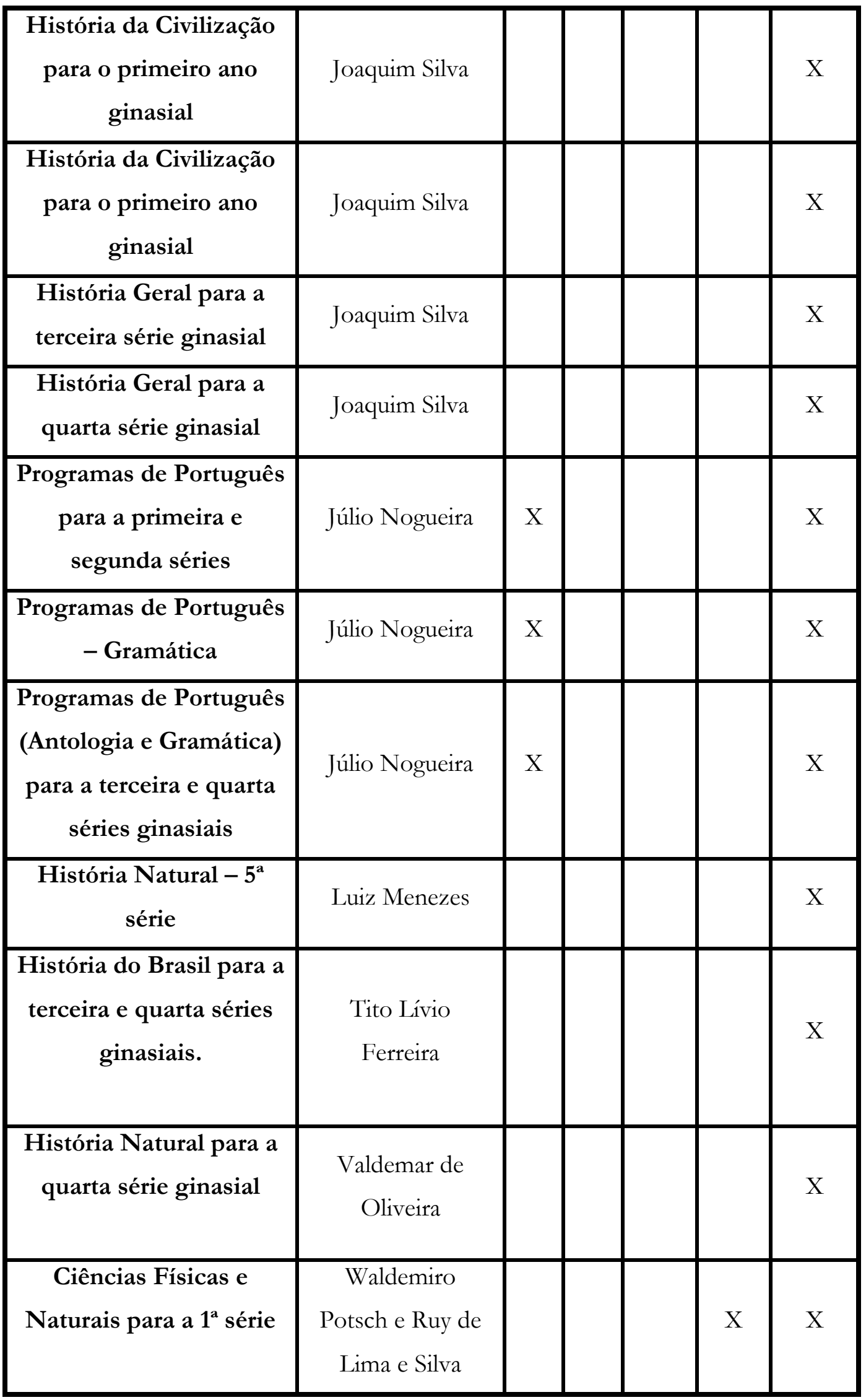


Fonte: Elaborado pelo autor.

\section{Notas:}

* Organizado por critério de autor.

introduz a obra o autor ressalta que "não se escraviza ao programa oficial, mas procura interpretá-lo da maneira mais racional". ${ }^{39}$ O programa oficial de Geografia para a série vem logo em seguida.

Na edição de 1954 da mesma obra há a indicação "de acordo com os novos programas, conforme portaria $\mathrm{n}^{\circ}$ 966, de 2/10/1951 e 1045, de 14/12/1951". Na "Explicação", Azevedo discorda da recente mudança dos programas: "Não nos parece haver sido feliz a recente reforma dos programas do ensino secundário, no que se refere ao estudo da Geografia na $2^{\mathrm{a}}$ série ginasial. Seria preferível que se conservasse o programa anterior, tal como estava". ${ }^{40}$ A discordância do autor, contudo, volta-se mais ao aspecto da divisão e organização do conteúdo, sem referência às instruções metodológicas. Na sequência, registrará que preferiu interpretar o programa à sua maneira, sem perder sua essência. $\mathrm{O}$ programa do curso é indicado de acordo com a legislação.

Programas de Português para a primeira e segunda séries, de Júlio Nogueira, lançado pela Companhia Editora Nacional em 1938, traz os programas expedidos pelo Governo Federal e pelo Instituto de Educação e apresenta uma página com dois textos voltados ao docente.

Em “A orientação deste livro", o autor informa que "o atual programa para o ensino de português é comum às duas primeiras séries" e que o livro segue este direcionamento. Assim, "os docentes, para a primeira série, estabelecerão um mínimo, tomando as noções que lhe parecerem profícuas para a maioria da classe". ${ }^{41}$

Logo abaixo, sob o título "Método para todas as lições" o autor apresenta como a obra está organizada e indica ao professor formas de desenvolver o conteúdo. O livro exibe, após cada lição, trechos de textos de renomados autores das letras nacionais. Nogueira sugere ao mestre: "Tais trechos [...] devem ser lidos, em primeiro lugar, pelo professor. Em seguida, este verificará se a classe entendeu a leitura, para o que poderá determinar que alguns alunos

${ }^{39}$ AZEVEDO, Aroldo de. Geografia: para a quinta série secundária. 3 ed. São Paulo: Companhia Editora Nacional, 1937, Explicação.

40 AZEVEDO, 1937, p. 9.

${ }^{41}$ NOGUEIRA, Júlio. Programas de Português: para a primeira e segunda séries. São Paulo: Companhia Editora Nacional, 1938, p. 11. 
façam um resumo do que ouviram". O autor instrui o docente a explicar "a significação de algum termo desconhecido". ${ }^{42}$ Outras obras do mesmo autor analisadas ${ }^{43}$ também trazem textos voltados ao mestre.

Percebe-se no texto do professor Júlio Nogueira uma preocupação metodológica que visa tanto instrumentalizar o docente no uso do compêndio, quanto instruí-lo na maneira de desenvolver a aula.

De todos os livros analisados, apenas dois trazem trechos das instruções metodológicas confeccionadas pelo governo federal.

Em Ciências Físicas e Naturais para a $1^{\text {a }}$ série, de Waldemiro Potsch e Ruy de Lima e Silva, editado em 1933 pela Tip. de A Encadernadora S.A, do Rio de Janeiro, já na folha de rosto há a indicação "rigorosamente de acordo com o programa elaborado pelo Ministério da Educação e Saúde Pública”. Em seguida, são reproduzidos os dois primeiros parágrafos das orientações didáticas, com a informação no final de tratar-se das "instruções elaboradas pelo Ministério da Educação e Saúde Pública". O texto aconselha o docente a "desenvolver nos alunos, o hábito da experimentação e da observarão atenta dos fenômenos naturais, estimulando-lhes os dotes da imaginação, a argúcia do raciocínio e a habilidade nas realizações práticas". ${ }^{4}$

O maestro Heitor Villa-Lobos escreveu Solfejos - 2 volume, lançado por "Irmãos Vitale Editores" em 1946. ${ }^{45}$ A obra contém um prefácio do autor e traz a íntegra da Portaria $n^{\circ}$ 300, de 7 de maio de 1946, que aprovou instruções e unidades didáticas do ensino de canto orfeônico nas escolas secundárias. Além do programa para as quatro séries do curso ginasial, a portaria traz orientações sobre a organização das aulas e sobre os exercícios a serem desenvolvidos: "Estes exercícios versarão sobre elementos de teoria musical, um trecho de obra didática, hinos e canções, de acordo com a orientação traçada pelo Conservatório Nacional de Canto Orfeônico. ${ }^{46}$

\footnotetext{
${ }^{42}$ NOGUEIRA, 1938, p. 11.

${ }^{43}$ Programas de Português - Gramática (1944), Programas de Português (Antologia e Gramática) para a terceira e quarta séries ginasiais (1955).

${ }^{44}$ POTSCH, Waldemiro; LIMA E SILVA, Ruy de. Ciências Físicas e Naturais: para a $1^{a}$ série. 5 ed. Rio de Janeiro: Tip. de A Encadernadora S.A ,1933, s/p.

${ }^{45} \mathrm{Na}$ quarta capa da edição analisada há uma relação das obras escritas por Villa-Lobos para esta editora: Solfejos ( $1^{\circ}$ volume e $2^{\circ}$ volume), Canto Orfeônico ( $1^{\circ}$ volume e $2^{\circ}$ volume), Guia Prático (Estudo folclórico musical), Guia Prático (Para piano) e Música Sacra $\left(1^{\circ}\right.$ volume).

${ }^{46}$ VILLA-LOBOS, Heitor. Solfejos $-2^{o}$ volume. São Paulo, Rio de Janeiro: Irmãos Vitale Editores, 1946, p. VI.
} 
Aos alunos que entrarem na $2^{a}$ série sem nenhum conhecimento do canto orfeônico, a orientação estatal sugere ao professor: "Esses alunos aprenderão por audição os hinos oficiais e canções patrióticas, caso os elementos técnicos musicais não lhes sejam suficientes." $^{47}$

Com exceção dos trabalhos de Aroldo de Azevedo e Júlio Nogueira - que procuram estabelecer diálogos com o professor através de textos elaborados pelos próprios autores as demais obras limitam-se a enfatizar sua vinculação aos programas oficiais. Pode-se pensar essa menção constante aos programas como consequência das exigências do novo mecanismo de seleção e avaliação dos livros escolares criado pelo Governo Federal.

Em julho de 1940, o Ministro da Educação, Gustavo Capanema, presidiu a reunião de instalação da Comissão Nacional do Livro Didático (CNLD), cuja finalidade era fiscalizar a literatura didática usada nas escolas do país a partir de dois aspectos: o político-ideológico e o técnico-científico. Estava dividida em nove seções - com três a cinco membros cada que se responsabilizavam por avaliar as obras de sua especialidade. ${ }^{48}$ Mesmo tendo suas atribuições questionadas e alteradas, a CNLD continuou a existir até 1969, como instância de aprovação de livros escolares.

A análise dos livros escolares era feita a partir de uma ficha de avaliação dividida em quatro blocos - Formato, Material, Feição Gráfica e Valor Didático. Cada bloco se subdividia em itens e subitens. Um ponto de avaliação da CNLD era exatamente o ajustamento ao programa. ${ }^{49}$ Informações auxiliares ao professor ou orientações quanto à metodologia de ensino não figuravam como exigências no processo de seleção.

O livro didático era um material essencial para o trabalho docente, constituindo-se, muitas vezes, no único instrumento de que o professor dispunha para o preparo das aulas, bem como para atualizar-se sobre os conhecimentos da disciplina que ministrava. Apesar das tiragens limitadas e das dificuldades de distribuição num país continental, o livro chegava ao professor. Poderia, portanto, ser importante veículo de divulgação de recomendações metodológicas - seja as prescritas pelo Estado, através da pura e simples transcrição destas, como ocorre no livro de Waldemiro Potsch e Ruy de Lima e Silva e no do maestro VillaLobos, seja por meio de prefácios, introduções e notas elaboradas pelos próprios autores dos

\footnotetext{
${ }^{47}$ VILLA-LOBOS, 1946, p. VI.

${ }^{48}$ FILGUEIRAS, 2011, p. 37.

${ }^{49}$ FILGUEIRAS, 2011, p. 45.
} 
livros. O já citado Guy de Hollanda, um entusiasta das "Instruções Metodológicas" que acompanharam as Reformas, afirmou que as lançadas em 1931 padeceram de dois males, um deles a falta de conveniente divulgação.

\section{Livros didáticos e modelos pedagógicos}

A partir de meados dos anos 1920 o paradigma pedagógico que serviu de referência para a institucionalização da educação paulista (e de outras partes do Brasil) começou a dar sinais de esgotamento. A chamada Pedagogia Moderna - concebida como arte de ensinar, baseada no fornecimento e imitação de modelos - perde espaço.

O abalo desta concepção pedagógica ocorreu, segundo Marta Carvalho, a partir da pretensão de se construir uma pedagogia cientifica, que teve como efeito colateral um processo de autonomização dos métodos de ensino.

Com toda a precaução que a matéria exige, é possível sustentar que a autonomização dos métodos que marca o solapamento dessa pedagogia como arte de ensinar deu-se em duas direções distintas, mas complementares: a de um progressivo didatismo; e a de uma hipervalorização das "ciências" da educação como fundamentos da prática docente. ${ }^{50}$

Um novo modelo emerge. Marta Carvalho o caracteriza:

A chamada pedagogia da Escola Nova, que começa a se difundir no país em meados da década de 20 , pretende subsidiar a prática docente com um repertório de saberes autorizados, propostos como os seus fundamentos ou instrumentos. ${ }^{51}$

Este deslocamento provocou mudanças na própria forma de difusão dos modelos pedagógicos. "O livro único de pedagogia, espécie de manual em que se compendia o conjunto dos saberes representados como necessários e suficientes ao exercício da prática docente, tende a ser substituído por coleções pedagógicas". ${ }^{52} \mathrm{O}$ objetivo de tais publicações

\footnotetext{
${ }^{50}$ CARVALHO, Marta Maria Chagas de. Modernidade pedagógica e modelos de formação docente. São Paulo em Perspectiva, v. 14, n. 1, p. 114, 2000.

${ }^{51}$ CARVALHO, 2000, p. 111.

${ }^{52}$ CARVALHO, Marta Maria Chagas de. A Caixa de Utensílios e a Biblioteca: Pedagogia e Práticas de Leitura. In: VIDAL, Diana G.; HILSDORF, Maria Lúcia S. (Orgs.). Tópicas em História da Educação. São Paulo: EDUSP, 2001, p. 155.
} 
é constituir uma cultura pedagógica que sirva de fundamento e de critério para o exercício do professor em sala de aula.

Num quadro em que o Estado passa a prescrever Programas de Ensino, Currículos e Instruções Metodológicas e o paradigma pedagógico sofre transformações, cabe indagar: de que forma os livros didáticos dialogam com o novo referencial pedagógico?

Nos livros didáticos voltados ao secundário foi possível notar que são raras as interlocuções com o professor e, quando ocorrem - em geral, por meio de prefácios e apresentações -, caracterizam-se pelo aspecto sucinto e pouco detalhista. Pouco comum, também, é a divulgação das direções metodológicas oficiais. Observa-se, no entanto, a preocupação de autores e editores em demonstrar que o conteúdo de seus livros segue, rigorosamente, as determinações governamentais.

Pode-se cogitar que o conteúdo das instruções presentes nos compêndios escolares se relacione ao novo modelo pedagógico que se estabeleceu a partir de meados dos anos 1920, no qual o espaço privilegiado para a divulgação de métodos e técnicas de ensino passou a ser as Bibliotecas Pedagógicas:

\begin{abstract}
Nessa política, a Biblioteca de Educação é coleção que compendia os saberes pedagógicos necessários à transformação da mentalidade e da prática do professorado. Nela, a pedagogia como "arte de ensinar" é figura do passado. Formar o professor é transformar a sua mentalidade. É fazêlo percorrer o caminho que leva à superação de suas concepções sobre a atividade do aluno, deslocando-as do terreno constituído por uma pedagogia centrada no exercício das faculdades da criança. É levá-lo à compreensão das novas finalidades sociais da escola. ${ }^{53}$
\end{abstract}

Os livros didáticos parecem refletir, ainda que sutilmente e não de maneira homogênea, a proposta de se constituir uma nova cultura pedagógica, cujo objetivo era, conforme Carvalho, "fornecer um repertório de informações e de referenciais críticos para o professor, orientando-lhe a leitura como prática inventiva rebelde à prescrição de modelos". ${ }^{54}$

${ }^{53}$ CARVALHO, 2001, p.165.
${ }^{54}$ CARVALHO, 2001, p.154. 


\section{CONSIDERAÇÕES FINAIS}

A partir de 1930, o Governo Federal intensificou sua atuação no sentido de direcionar a educação nacional. Por intermédio das Reformas Francisco Campos (1931) e Gustavo Capanema (1942) e da Portaria Ministerial n 1.045 (1951) o Poder Público estabeleceu, além dos Programas Curriculares, as chamadas Instruções Metodológicas visando determinar modos de ensinar. O monitoramento sobre a produção e o conteúdo dos livros didáticos se deu através da criação, em 1938, da Comissão Nacional do Livro Didático (CNLD).

Nos livros editados entre 1930 e 1960 dirigidos ao ensino secundário, percebe-se a ação dos mecanismos de avaliação estatais através da preocupação de autores e editores em demonstrar que suas obras estavam de acordo com os programas oficiais. Os textos direcionados ao professor, em geral prefácios e apresentações, não são frequentes e têm aspecto pouco detalhista. As Instruções Metodológicas raramente aparecem nos livros escolares o que indica que estes não eram vistos pelo Estado como veículos de divulgação de suas prescrições quanto aos métodos de ensino.

A alteração do paradigma pedagógico a partir de meados dos anos 1920, com a emergência dos princípios do escolanovismo, resultou na proposição de uma pedagogia que buscava levar o professor a compreender as novas finalidades sociais da escola e as Bibliotecas Pedagógicas se constituíram no principal meio de difusão de métodos e técnicas de ensino. Poderia se pensar que o teor das orientações observadas nos livros didáticos retratam, ainda que de maneira tênue e não uniforme, este novo referencial. 